Área Abierta. Revista de comunicación

audiovisual y publicitaria

ISSN: 1578-8393

\title{
Reutilización de la ficción sonora en la Cadena Ser. El caso de Podium Podcast
}

\author{
Miriam Rodríguez Pallares ${ }^{1}$
}

Recibido: 16 de septiembre de 2016 / Aceptado: 11 de noviembre de 2016

Resumen. El género de ficción fue protagonista en la programación radiofónica de la posguerra por adaptación al imperativo dictatorial en los indicativos de titularidad privada. En este contexto, la Cadena SER abanderó el radio drama en España, cuyos años dorados se concentraron entre las décadas de los cuarenta y los setenta. A colación del resurgir de este género en la oferta mediática nacional, se plantea el objetivo de investigar si las nuevas formas de producción y distribución digitales facilitan no solo la oferta de nuevos contenidos de ficción, sino también y especialmente la reutilización de fondos de archivo de la Cadena SER, a través del estudio de Podium Podcast. Para ello, se analiza, en primer lugar, el modelo de gestión de contenidos del grupo y, después, la visibilización de fondos de archivo en el caso analizado. Con un enfoque cualitativo, la metodología aplicada se fundamenta en las entrevistas en profundidad y la observación indirecta. Los resultados obtenidos permiten concluir que desde Prisa Radio se reconoce el valor de este género desde el punto de vista documental y, aunque olvidados durante años, recientemente se apuesta por su reutilización contextualizada de acuerdo a criterios periodísticos y culturales, fundamentalmente a través de podcasts.

Palabras clave: Radio drama, Cadena SER, gestión de contenidos, documentación, archivo radiofónico, podcasting, Podium Podcast

\section{[en] Reusing of Radio Drama in Cadena Ser. The Case of Podium Podcast}

\begin{abstract}
Fiction genre was an important element of radio programming after Spanish Civil War because of dictatorship's legal imperative. In this context, Cadena SER was the most important Spanish producer of radio dramas, whose golden years were concentrated between the 1940's and 1950's. Recently, fiction contents have resurfaced in the Spanish media landscape, and this article aims to know if new ways of digital production and distribution facilitate not only the offer of new fiction contents but also the reuse of radio drama contents which are preserved in the Prisa Radio's content management system, through the case study of Podium Podcast. To that end, firstly, it is analyzed the content management model and then the visibility of these contents in the analyzed case. This research is based on in-depth interviews and non-participating observation. The results obtained allow us to conclude that this radio broadcasting company recognizes their fiction contents value, which are being managed and preserved and although they were forgotten for years, in the recent period, Prisa Radio is reusing these contents according to journalist and cultural criteria, mainly through podcasts.
\end{abstract}

Keywords: Radio Drama, Cadena SER, Content Management, Documentation, Radio Archive, Podcasting, Podium Podcast

1 Universidad Internacional de La Rioja (España)

E-mail: miriam.rodriguez@unir.net 
Sumario. 1. Arte, radio y ficción en España. 2. Objetivos, metodología y límites. 3. La gestión de contenidos de ficción en la Cadena Ser. 4. Reinvención y reutilización del género de ficción: Podium Podcast. 5. Conlusión. 6. Bibliografía. 7. Entrevistas.

Cómo citar: Rodríguez Pallares, M. (2017) Reutilización de la ficción sonora en la Cadena Ser. El caso de Podium Podcast, en Área Abierta. Revista de comunicación audiovisual y publicitaria 17 (1), 83-98. http://dx.doi.org/10.5209/ARAB.53445

\section{Arte, radio y ficción en España}

En ocasiones tener es ser. Aunque puede parecer inapropiado plantear una equivalencia tan genérica, cuando hablamos de la historia de un país, disociar ambos verbos reporta un error conceptual que afecta a las bases de todo hipotético argumento analítico. Cualquier disertación presente, pasada o futura de la realidad referencial o de un fragmento de la misma implica siempre un contexto histórico, sin ello, cualquier aportación crítica posterior a la descripción pierde sentido. Por lo tanto, la historia que tiene un país condiciona lo que ese país es.

El desarrollo de la radio en España está incuestionablemente sujeto a los hechos que han condicionado la propia historia del país y perfilado su idiosincrasia nacional. Se considera que la primera emisión radiofónica continuada fecha del 14 de noviembre de 1924 - en plena dictadura de Primo de Rivera-, y se atribuye a la estación EAJ-1 Radio Barcelona - aunque Radio Ibérica había emitido ya un año antes- . La democratización del servicio radiofónico no fue instantánea, consecuencia del elevado precio de los aparatos receptores, por un lado, y de las restricciones en la cesión de licencias de emisión, por el otro (Ayuso, 2013: 168). Esta situación inicial se mantuvo tras la Guerra Civil Española (1936-1939), con el agravante de la censura que el período dictatorial implicó a nivel informativo.

Fue precisamente de la mano del bando sublevado como nació Radio Nacional de España (RNE), trece años más tarde de la primera emisión radiofónica por parte de una sociedad privada — precursora de la Cadena SER y estandarte generalista de Prisa Radio- . Fue el 19 de enero de 1937, desde Salamanca y con la voz de Fernando Fernández de Córdoba como identificativo sonoro. Pese a que desde entonces convivieron las emisiones radiofónicas de titularidad pública y de titularidad privada, las disposiciones del movimiento dictatorial otorgaron el monopolio informativo a RNE, reduciendo la cobertura radiofónica del sector privado al entretenimiento (Balsebre, 2001; Franquet, 1986).

Aún con ello, los identificativos radiofónicos ajenos al servicio del régimen franquista no cesaron su actividad y trataron de explotar el abanico de posibilidades que el marco regulador les permitía. En este contexto, la ficción radiofónica alcanzó su máximo esplendor, logró fidelizar a la audiencia y posicionó a actores y locutores como Pedro Pablo Ayuso, Matilde Vilariño, Juana Ginzo, Teófilo Martínez o Matilde Conesa, entre las estrellas del momento. Compañías de teatro nutrieron programas dramáticos radiofónicos tan reconocibles como El teatro del aire, dirigido por Antonio Calderón en Radio Madrid, o El teatro invisible, dirigido por Juan Manuel Soriano en RNE Barcelona. Fue la «edad de oro de la radio dramática española» (Ayuso, 2013: 168), convertida entonces en protagonista de la programación y que gozó, además, de sobresaliente atractivo para la inversión publicitaria. 
El género, no obstante, perdió impulso paulatinamente, alentado por el asentamiento de la televisión - aunque en los años anteriores se realizaron emisiones de prueba, fue en 1956 cuando TVE comenzó a emitir regularmente-y el cine en España, bajo una justificación construida con argumentos económicos y el desinterés del espectador. No obstante, las opiniones vertidas al respecto son múltiples y variadas, entre ellas la de Federico Volpini, exdirector de Radio 3, quien consideró como explicación de la decadencia del género que al éxito de la imagen en movimiento se sumaban otros dos elementos: la ausencia de interés del medio público por impulsar servicios que no reportasen votos directos, y la también falta de interés del sector privado por alentar producciones que no dependiesen directamente de ellos (Gamarra, 2015).

De cualquiera de las maneras, la realidad es que el radio drama cedió su lugar en el pódium de la programación española, más inmediata, más informativa y menos creativa; contrariamente a lo ocurrido, por ejemplo, en Inglaterra, donde la $\mathrm{BBC}$ no solo no ha dejado caer en el olvido a este género, sino que goza incluso de departamento propio y significativa partida presupuestaria (Lewis, 2004: 162).

Precisamente en relación a esta última idea, el radio teatro —una de las manifestaciones de ficción radiofónica, no la única (Guarinos, 1999; Rodero y Soengas, 2010; Martínez-Costa y Díaz Unzueta, 2005) - es un género no exento de debate en lo que a su análisis se refiere. Se identifica, por un lado, con un fin educativo (Brecht, 1993, citado por Huwiler, 2005: 47), esto es, se analiza como la traslación de un género literario al código hablado y, por el otro, se reconoce como un arte por derecho propio, cuyas técnicas narrativas le confieren particularidades propias y exigen un análisis diferencial (Cazeaux, 2005; Oesterlen, 2008; Lewis, 2004; Huwiler, 2005 y 2010). En cualquiera de los casos, una apuesta por la creatividad radiofónica (Rodero, 2005: 141).

Sin embargo, aun con altibajos, la ficción parece volver a recuperar visibilidad en la programación de la radio española ${ }^{2}$, siempre sin dejar de otorgar protagonismo a su cualidad más identificable, la misma que para unos engrandece a este género y para otros lo convierte en irrelevante o insatisfactorio: la ausencia de imagen (Cazeaux, 2005: 157). Desde las primeras emisiones de radio drama — atribuidas a Las aventuras de una parisién en Madrid (emitida por primera vez el 16 de marzo de 1926 por la ahora Prisa Radio), por unos, y a La muerte de míster Stay (emitida por primera vez en enero de 1926 por Radio Ibérica), por otros, (Ventín, 2008)-, sus manifestaciones en los grandes indicativos radiofónicos generalistas nacionales han evolucionado de la mano de las nuevas tecnologías y la narrativa transmedia. Por un lado, potencian la innovación creativa en una radio ahora también pensada para la difusión digital, asincrónica, fragmentada y multiformato que, de la mano del hipertexto y las redes sociales, fomentan la comunicación bidireccional (Rodríguez, 2015; Cebrián, 2001; Martínez, 2011; Salaverría, 2015) y, por otro, facilitan la visibilidad del archivo sonoro sin colisionar con las directrices que vertebran la parrilla radiofónica tradicional.

2 Ejemplos de ello son Ficción Sonora, puesta en marcha por RNE y La Casa Encendida, o la serie radiofónica Tiempo de Valientes. El diario sonoro de Julián Martínez en Cuba (1898) que complementa, como ejemplo paradigmático de narración transmedia, a la serie televisiva El Ministerio del Tiempo de RTVE. 


\section{Objetivos, metodología y límites}

El objetivo general de este artículo es identificar si las nuevas formas de producción y distribución digitales facilitan la reutilización de fondos de ficción radiofónica de archivo en la Cadena SER y, por extensión, de Prisa Radio. Para ello, se toma como estudio de caso Podium Podcast, nuevo modelo de negocio digital del grupo. La selección del caso de estudio responde a una doble justificación. En primer lugar, la historia radiofónica confirma el relevante papel de la Cadena SER como divulgador de contenidos dramáticos, lo que hace presuponer un archivo robusto de este género y, en segundo lugar, la selección se basó en la premisa de que los medios de propiedad privada fundamentan su actividad en el fin lucrativo, pero sin que ello implique perder de vista sus responsabilidades sociales (Faustino, 2008: 58). Entre ellas, custodiar la memoria histórica como coadyuvante de sus fines formativo, informativo y de entretenimiento (Nieto e Iglesias, 2000).

El estudio surge de las siguientes hipótesis iniciales:

1. Los contenidos de ficción radiofónica de la Cadena SER se conservan en diferentes formatos, no todos digitalizados, lo que dificulta su recuperación y reutilización.

2. La visibilidad de contenidos de archivo de ficción radiofónica es muy escasa en la programación on air, pero las nuevas formas de consumo digital, asincrónico y fragmentado, se están explotando para ofrecer contenidos que no encuentran cabida en la programación tradicional, entre ellos, los archivos de radio teatro.

Dichas hipótesis, en su forma interrogativa, cumplen función de research questions (RQ) y para darles respuesta se plantearon los siguientes objetivos específicos:

a) Identificar y describir el modelo de gestión de contenidos en la Cadena SER prestando atención a la custodia (o no) de la producción de ficción, conditio sine qua non es posible su reutilización, lo que implica economía de tiempo y trabajo.

b) Identificar las estrategias de reutilización y explotación del archivo de ficción de la Cadena SER a través del nuevo proyecto de Prisa Radio: Podium Podcast.

La base epistemológica de este trabajo responde a un enfoque metodológico cualitativo, esto es, no se trata de alcanzar conclusiones con rango de norma, sino de aplicar una lógica inductiva a los datos obtenidos tras un proceso de observación. La metodología aplicada para la consecución de los objetivos planteados responde al estudio de caso, un método que, según Stake, es «existencial (no determinista) y constructivista», y pone el énfasis en la interpretación (Stake, 2007: 46). Las técnicas empleadas fueron la entrevista en profundidad de tipología semiestructurada (Tabla 1) y la observación indirecta, a fin de corroborar los datos a través de otras fuentes (Tamayo y Tamayo, 1981: 183). Las entrevistas en profundidad se realizaron a María Jesús Espinosa, responsable del proyecto Podium Podcast, y Ana Martínez, responsable del servicio de Documentación de la Cadena SER. 


\begin{tabular}{|l|l|}
\hline \multicolumn{2}{|c|}{ Estructura de la entrevista en profundidad* } \\
\hline \multicolumn{1}{|c|}{ Primer nivel de descripción } & \multicolumn{1}{|c|}{ Segundo nivel de descripción** } \\
\hline Plano descriptivo & $\begin{array}{l}\text { Estructura de la empresa propietaria. } \\
\text { Origen, evolución y desarrollo del } \\
\text { departamento. } \\
\text { Herramientas de gestión. }\end{array}$ \\
\hline Plano organizativo & $\begin{array}{l}\text { Estructura y organigrama del } \\
\text { departamento. } \\
\text { Alcance y vinculación entre } \\
\text { departamentos. }\end{array}$ \\
\hline Plano funcional & $\begin{array}{l}\text { Descripción del modelo de trabajo. } \\
\text { Lógica de gestión, recuperación y } \\
\text { visibilidad de contenidos. } \\
\text { Nuevos modelos de negocio. } \\
\text { Tratamiento, creación y reutilización de } \\
\text { contenidos de ficción radiofónica. }\end{array}$ \\
\hline $\begin{array}{l}\text { * La muestra de los profesionales entrevistados fue seleccionada de acuerdo } \\
\text { a criterios de responsabilidad organizativa y funcional. Las entrevistas se } \\
\text { realizaron de forma personal a lo largo del mes de julio de 2016. } \\
\text { ** La tabla refleja los dos primeros niveles de descripción de las entrevistas de } \\
\text { un total de tres. }\end{array}$ \\
\hline
\end{tabular}

Tabla. 1. Diseño de la entrevista semiestructurada [Fuente: elaboración propia].

En este apartado, resulta importante mencionar dos limitaciones atribuibles a este estudio. Primeramente, que la muestra se reduce a un solo caso de análisis, por lo tanto, los resultados obtenidos son sintomáticos, pero no pueden ser extrapolables a la generalidad. Y, en segundo lugar, no se plantea, en esta ocasión, un análisis cuantitativo en relación a la producción de ficción sonora de la Cadena SER, ni una descripción pormenorizada de su tratamiento documental; el objetivo se limita, por lo tanto, a identificar si este género cumple los patrones de relevancia para pasar a engrosar el repositorio de Prisa Radio y averiguar cuál es la estructura de su sistema de gestión de contenidos (CMS por sus siglas en inglés, content management system) para vincularlo, después, con la reutilización de la ficción de archivo, prueba de su actividad y memoria colectiva.

\section{La gestión de contenidos de ficción en la Cadena SER}

La gestión de contenidos es una actividad especialmente relevante en un contexto en el que el modelo de comunicación digital marca tanto las relaciones sociales como las 
estrategias de gestión, producción y distribución. Se considera un proceso complejo en el que confluyen «componentes tecnológicos, estrategia empresarial y prácticas profesionales» (Fernández, Rodríguez y Rodríguez, 2013: 393). Su objetivo es el tratamiento y la conservación de datos e información estructurada y no estructurada lo que, por definición, incluye también el conocimiento generado o necesario en el contexto digital organizativo.

Cuando se aplica a un medio de comunicación, se puede identificar una dualidad de fines en las prácticas vinculadas a la gestión de sus contenidos, activos intangibles, fuente y prueba de su actividad (Fernández, et. al., 2013: 393):

El primero es el fin funcional, centrado en la mejora de la distribución, la reutilización y la revalorización de la producción mediática o susceptible de serlo y, por lo tanto, de su marca en el mercado. Sus objetivos se resumen en la tríada: informar, formar y entretener con calidad (Nieto e Iglesias, 2000). Responde al intento de optimización del trabajo y de los recursos propios de una organización de acuerdo a la idea de producir contenidos una vez y publicarlos en tantos canales $\mathrm{y}$ tantas veces como sea posible (POPE/produce once and publish everywhere), lógica que, aparejada, conlleva el enriquecimiento de la oferta mediática a partir de contenidos de archivo.

El segundo es el fin estratégico, enfocado a la gestión de la producción de las diferentes áreas de actividad de la empresa. En este caso, supera los límites de la muestra - excede, por lo tanto, los límites de este estudio_-, vela por la integración de la actividad explicitada de la empresa y colabora, por lo tanto, con la democratización del conocimiento organizacional (Rodríguez Pallares, 2016). Este fin se fundamenta en la «cultura de lo intangible», lógica que está dejando paso a una nueva forma de generar riqueza (Carrillo y Nuño, 2010: 124).

Anteriormente comentábamos las particularidades de la Cadena SER en lo relativo a la producción de ficción sonora y al éxito de este género narrativo a mediados del siglo XX en España. Parece que la lógica insta a pensar que los contenidos de este género cuentan con valor suficiente desde los puntos de vista cultural, formativo y empresarial para gozar de un tratamiento especial en el archivo de Prisa Radio y una visibilidad destacada atendiendo a los ya mencionados fines sociales de los medios. Siguiendo el orden de los objetivos planteados, a continuación describimos el modelo de gestión de contenidos o documental de Prisa Radio, prestando atención a sus particularidades e identificando la existencia o no de fondos catalogados como ficción sonora.

La Cadena SER dispone de un servicio de documentación propio, ubicado en Madrid y reconocido desde 1988, año en el que pasa a formar parte del accionariado de Prisa Radio. El caso de este departamento es particular como consecuencia de la propia estructura societaria, por un lado, y de la lógica de trabajo, por el otro.

Prisa Radio es un grupo internacional al que pertenecen marcas radiofónicas presentes en Latinoamérica, Estados Unidos y España. Aunque inicialmente el archivo respondía al conjunto de contenidos de producción nacional, la expansión del grupo más allá del Atlántico implicó la multiplicación de las fuentes responsables del engrosamiento de Enciclomedi@. Esta base de datos es de libre acceso y consulta para todas las marcas radiofónicas de Prisa Radio, pero tan solo cuatro países, junto con España, cuentan con la capacidad de nutrir al sistema de gestión de contenidos digitales, estos son México, Argentina, Chile y Colombia, cuya actividad gestora de contenidos depende de W Radio, Continental, ADN y Radio 
Caracol, respectivamente (Gráfico 1). El departamento de Documentación es, por lo tanto, particular por su carácter internacional y, aunque el interés de este estudio es la conservación y reutilización de contenidos de ficción sonora de la Cadena SER, es relevante comprender el alcance de su modelo de gestión de contenidos, condicionante de la estructura y la lógica de custodia de su archivo.

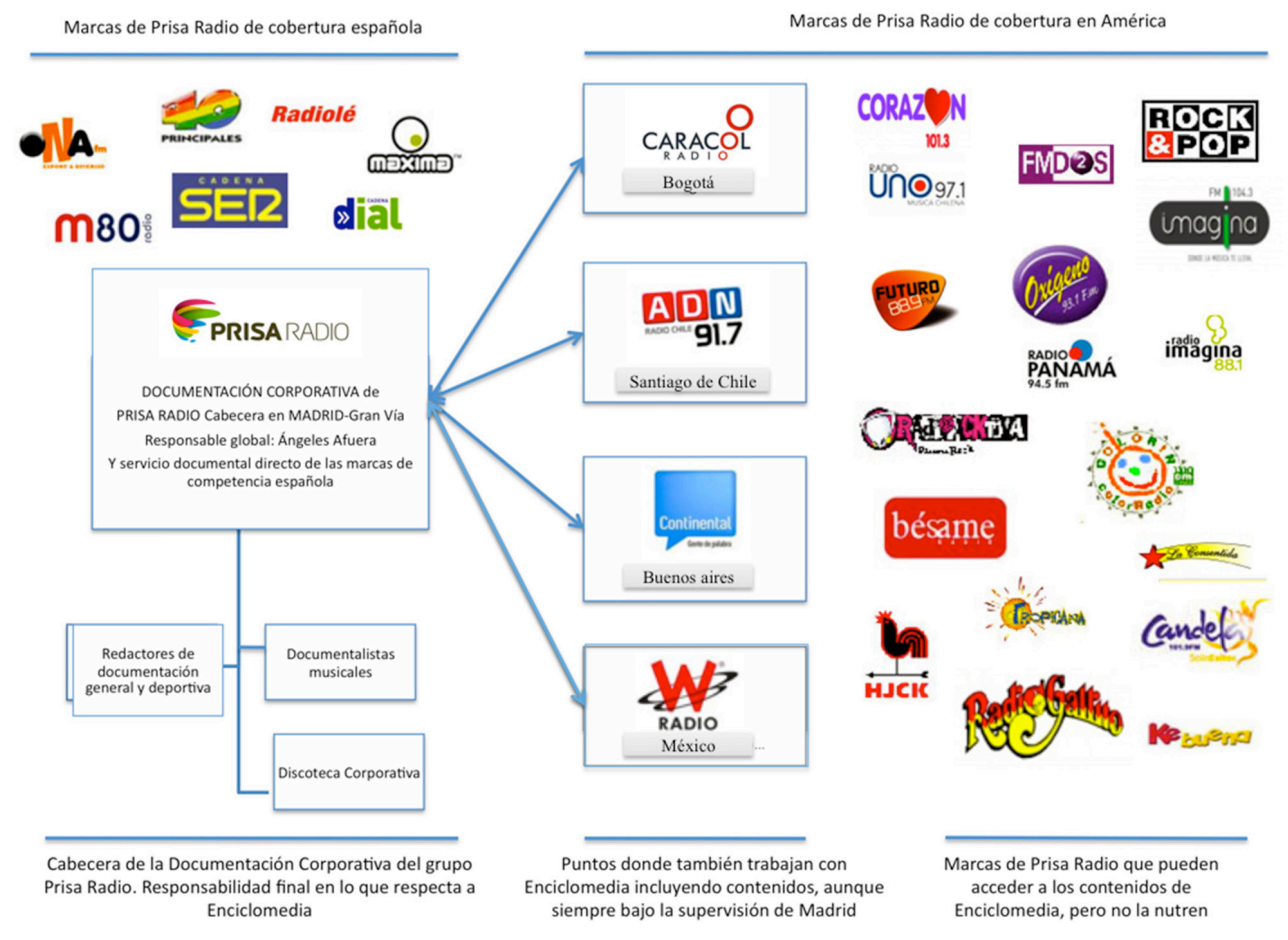

Figura 1. Roles y marcas radiofónicas de Prisa Radio [Fuente: Rodríguez Pallares, 2014].

No fue hasta octubre de 2004 cuando llegó el sonido digital a la Cadena SER, desde entonces todo lo que se conserva está en este formato, por ende, custodiado en bases de datos. La producción previa a dicha fecha se conserva en formatos físicos (cassette, cintas abiertas, CD, DAT). Son dos los argumentos que justifican que la reutilización de contenidos de archivo se lleve a cabo con tan poca celeridad. El primero es económico: el presupuesto que exige un proyecto de digitalización no se contempla como prioritario actualmente. El segundo es funcional: el archivo de la Cadena SER está vivo, es decir, las redacciones, tanto nacionales como locales, tienden a usarlo con frecuencia, con lo cual se plantea complejo ceder los archivos para su digitalización con el tiempo que ello supone de inactividad (Martínez Concejo, 2016). Sin embargo, aunque el histórico de la cadena no está digitalizado en su totalidad (Tabla 2), sí hay colecciones que fueron convertidas a formatos digitales (con la colaboración de SETI, empresa de consultoría y servicios 
tecnológicos), entre ellas el radio drama, o lo que es lo mismo, las producciones de ficción independientes y seriadas completas.

\begin{tabular}{|c|c|}
\hline \multicolumn{2}{|c|}{ Cadena Ser } \\
\hline \multicolumn{2}{|c|}{ Proceso documental } \\
\hline Políticas de selección y custodia & $\begin{array}{l}\text { La custodia de contenidos está } \\
\text { condicionada por el cumplimiento de } \\
\text { los derechos de autor y conexos: solo } \\
\text { se guardan en definitivo los contenidos } \\
\text { cuya autoría sea de la Cadena SER. } \\
\text { En caso de no ser así, se guardan } \\
\text { únicamente mientras se puedan } \\
\text { explotar de acuerdo a los derechos de } \\
\text { emisión adquiridos. } \\
\text { Solamente se guarda el continuo de la } \\
\text { emisión on air, los brutos se obvian } \\
\text { excepto en caso de que sean programas } \\
\text { o contenidos especiales. }\end{array}$ \\
\hline Digitalización de fondos & $\begin{array}{l}\text { La digitalización de fondos históricos } \\
\text { (previos a 2004) no está completa. Sin } \\
\text { embargo, sí están digitalizados en su } \\
\text { totalidad los contenidos dramáticos } \\
\text { históricos. }\end{array}$ \\
\hline \multicolumn{2}{|c|}{ Herramientas tecnológicas } \\
\hline Sistema de gestión de contenidos & $\begin{array}{l}\text { Enciclomedi@, CMS o MAM in- } \\
\text { house. }\end{array}$ \\
\hline Implantación & 1988. \\
\hline $\begin{array}{l}\text { Sistema integrado con el software de la } \\
\text { redacción }\end{array}$ & $\begin{array}{l}\text { Cuentan con dos herramientas } \\
\text { conectadas: Redacta, para la redacción, } \\
\text { y Enciclomedi@ para el servicio } \\
\text { documental. La primera surte de } \\
\text { contenidos a Enciclomedi@, que las } \\
\text { marcas radiofónicas de Prisa Radio } \\
\text { utilizan para sus consultas. }\end{array}$ \\
\hline \multicolumn{2}{|c|}{ Acceso y recuperación } \\
\hline Recuperación manual o automática & Automática en los fondos digitalizados. \\
\hline $\begin{array}{l}\text { Perfiles de acceso interno a los } \\
\text { contenidos }\end{array}$ & $\begin{array}{l}\text { Existen perfiles de acceso, habilitados } \\
\text { por nombre de usuario y clave. }\end{array}$ \\
\hline Canales de salida & $\begin{array}{l}\text { Solo para servicios de la corporación, } \\
\text { excepto en ocasiones puntuales } \\
\text { tarificadas - siempre que no se trate de } \\
\text { fines educativos o culturales-. }\end{array}$ \\
\hline
\end{tabular}




\begin{tabular}{|l|l|}
\hline \multicolumn{2}{|c|}{ Revalorización de la gestión de contenidos } \\
\hline $\begin{array}{l}\text { Creación de contenidos por parte de los } \\
\text { responsables del departamento }\end{array}$ & $\begin{array}{l}\text { Para la emisión on air, para la web y, } \\
\text { recientemente, para Podium Podcast. }\end{array}$ \\
\hline
\end{tabular}

Tabla 2. Resumen funcional del modelo de gestión de contenidos o documentación de Prisa Radio/Cadena SER [Fuente: elaboración propia].

Es preciso recurrir al marco legal vigente en España en lo que al archivo de contenidos mediáticos respecta. Así, la Ley General de Comunicación Audiovisual $7 / 2010$, de 31 de marzo, en su disposición adicional sexta dice que «los operadores de comunicación audiovisual estarán obligados a preservar y a conservar el archivo de imágenes en movimiento y audio» y añade, en su artículo 61.1, que «a los efectos de la correcta dilucidación de la responsabilidad administrativa, los prestadores del servicio deberán archivar durante un plazo de seis meses a contar desde la fecha de su primera emisión, todos los programas emitidos, incluidas las comunicaciones comerciales, y registrar los datos relativos a tales programas». De estas líneas se colige que la grabación y custodia del continuo de las emisiones radiofónicas están reguladas por ley en base a un criterio probatorio, esto es, se trata de garantizar la posesión de una copia de la emisión a fin de evitar conflictos legales y es, por tanto, competencia de cada empresa el tratamiento de dichos contenidos en términos documentales, así como su explotación y reutilización.

La producción radiofónica se describe atribuyendo metadatos a cada pieza y catalogándola de acuerdo a colecciones temáticas o materias. Todo contenido vinculado a la ficción sonora se incluye en la tipología de dramáticos. Esto implica que, en este cajón temático, primer nivel de descripción, se incluyen: radioteatro, secciones de ficción integradas en programas de otra naturaleza o seriales modernos. Las adaptaciones de teatro históricas — previas a la digitalización de 2004- se conservan bajo la tipología archivo histórico. Un segundo nivel de descripción identifica el contenido con el drama radiofónico. Aunque los contenidos dramáticos son custodiados en el archivo y han gozado de prioridad en términos de digitalización, las búsquedas conllevan más tiempo del que se presupone con el uso de descriptores, ya que se necesita revisar cada resultado de forma individual, en caso de buscar formatos específicos.

A fecha 29 de agosto de 2016, el número de entradas catalogadas como dramáticos en Enciclomedi@ asciende a 1.653, cifra que, como se decía anteriormente, no discrimina las digitalizaciones históricas y las producciones modernas, como Milenio 3 o Cuento de Navidad, así como las secciones de ficción sonora integradas en programas como Hoy por Hoy Madrid, A vivir que son dos dias, Negra y Criminal o El verano no existe.

Desde la perspectiva documental, es importante hacer mención a una debilidad del sistema de gestión mediática de Prisa Radio España: el departamento de Documentación de la Cadena SER - anteriormente denominado Gestión de Contenidos y, posteriormente, Documentación Corporativa - trabaja como departamento corporativo, esto es, con los contenidos de la emisión de cobertura nacional, así como con la producción de la programación local de Madrid. Estos 
son el origen de los fondos que se albergan en Enciclomedi@ — junto con los respectivos a los cuatro departamentos ubicados en América Latina-, el resto de las desconexiones territoriales funcionan de forma autónoma, y de su criterio depende el que sus producciones sean conservadas y gestionadas o contar únicamente con copias del continuo. Por lo tanto, a menos que las propias emisoras locales creen su propio modelo de gestión de contenidos o bien los envíen a Documentación de la Cadena SER para incorporarlos al archivo de Enciclomedi@, estos se perderán. Por esta razón, es posible encontrar en el archivo corporativo contenidos de ficción sonora creados por emisoras regionales a sabiendas de que son una selección.

\section{Reinvención y reutilización del género de ficción: Podium Podcast}

Quizás la iniciativa navideña de la Cadena SER, Cuento de Navidad, que apuesta por el radioteatro desde 2013 y emitida periódicamente todos los 25 de diciembre, pueda considerarse un resurgir de este género tras la decadencia de la producción a partir de la década de los setenta. Si bien el germen se encuentra en 2011, con la emisión de la obra Las bicicletas son para el verano ${ }^{3}$.

Sin embargo, la reutilización de fondos de ficción de archivo se considera anecdótica y puntual hasta la llegada de un nuevo proyecto, Podium Podcast ${ }^{4}$, una red global de podcast en español, tal y como se explica en su sitio web, que conjuga tecnología con innovación narrativa y reutilización de fondos de archivo. Se trata de una innovación narrativa porque presenta una estrategia de distribución seriada, facilita «el flujo de contenidos a través de múltiples canales» (Jenkins, 2003), conjuga diferentes signos de significación (sonoro, visual o interactivo) (Scolari, 2013: 24) y fomenta la participación de los oyentes a través de redes sociales. De tal modo, que se extienden las líneas argumentales al concepto transmediático y se fomenta la bidireccionalidad que convierte al consumidor también en productor, esto es, en prosumidor (Scolari, 2013: 27).

Podium Podcast es relevante para la difusión de contenidos de ficción de archivo porque facilita la oferta de productos que, bien por su extensión, por su temática, o por su antigüedad, no se contemplan en la programación tradicional. Por otro lado, puso el foco de atención en los archivos de ficción y despertó el interés de su rentabilización (Rodríguez, 2015) también en la programación tradicional, ejemplo de ello es que en el verano de 2016, el programa Ser o no Ser recuperó también del archivo histórico digitalizado cuatro capítulos de Teatro del Aire (Tres sombreros de copa, La dama boba, Casa de muñecas y Hamlet).

3 Obra de teatro de Fernando Fernán Gómez (1977) llevada a la gran pantalla por Jaime Chávarri (1984). Bajo la dirección de Emma Cohen, fue adaptada a la radio y emitida por la Cadena SER en 2011, con motivo de cumplirse el 80 aniversario de la Guerra Civil Española.

4 "El podcasting es una innovación que surge tras la fusión de dos tecnologías ya implantadas como el audio digital y el RSS. Esta unión permite la distribución y recepción automatizada de archivos de audio comprimido tras una suscripción por parte del usuario a través de un agregador - software o web - que lo permita. Una vez recibido este archivo puede ser reproducido tanto en equipos estables como en reproductores portátiles o teléfonos móviles" (Gallego, 2010: 19). 
Aunque los servicios radiofónicos online y el podcast de forma especial se presentaron desde sus inicios como una oportunidad para explotar la evolución de la radio bajo demanda, es decir, para innovar en la producción de contenidos digitales, el gran problema en España es que las emisoras no nativas de Internet han tendido a limitar la distribución de contenidos digitales a la propia emisión on air, sin crear contenidos únicos para este formato (Gallego, 2012: 25), a diferencia, por ejemplo, de Estados Unidos, donde el podcasting no solamente está asentado en la oferta mediática, sino que, además, goza de un seguimiento destacado ${ }^{5}$. Asumir esta nueva forma de producción de contenidos radiofónicos más alejados de la inmediatez informativa que impera en la oferta actual es el objetivo marcado en los orígenes de Podium Podcast, es decir, busca la creación y distribución de contenidos atemporales ${ }^{6}$. «Se trata de productos pensados exclusivamente para Internet, con nuevas narrativas radiofónicas que cuidan el sonido y apuestan por la calidad», como señala el sitio corporativo de la Cadena SER.

En la actualidad, Podium Podcast, a modo de repositorio de contenidos públicos, cuenta con cuatro grandes colecciones temáticas (Imagen 1): ficción, periodismo, entretenimiento y esenciales, nutridas en colaboración por las emisoras de Prisa Radio en México, Colombia, Chile, Argentina y España.

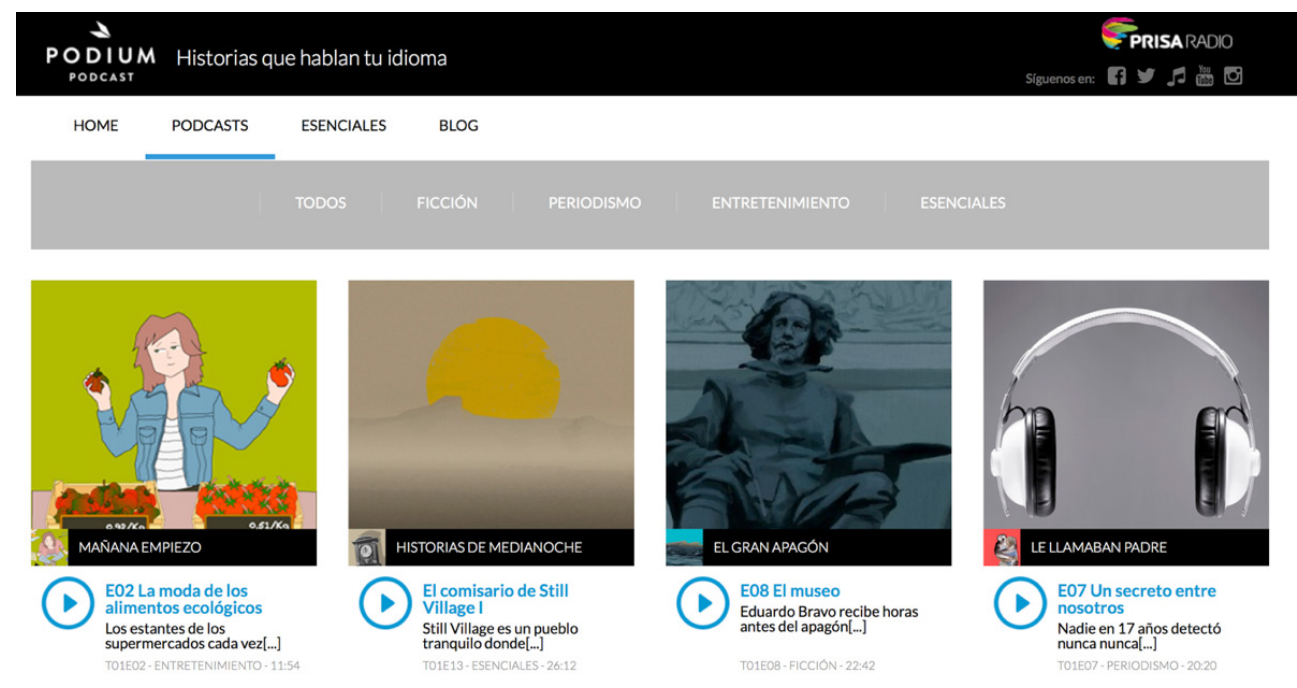

Figura 2. Website de Podium Podcast [Fuente: podiumpodcast.com].

5 Serial es un ejemplo paradigmático. Se trata de un proyecto nacido como extensión (spin-off) del programa de radio The American Life, presentado por Sarah Koening quien, además, lo coproduce con July Snyder. Serial es un proyecto de investigación periodística que narra los hechos que rodearon la muerte de Hae Min Lee, una adolescente americana, a manos, presuntamente de su ex pareja. Los resultados de la investigación se relataron de forma seriada y lograron fidelizar a más de un millón de oyentes semanales. Es, por tanto, un caso de éxito que exploró técnicas narrativas innovadoras en radio.

6 La oferta de servicios radiofónicos digitales pensados para su distribución a la carta bajo el formato podcast no es novedad en español —Carne Cruda, El Extrarradio, Radio Ambulante, entre otros-. Sin embargo, Podium Podcast trata de diferenciarse de sus análogos a través de la profesionalización de su servicio y de su alcance. 
Cada colección está compuesta a su vez por diferentes programas, organizados por capítulos, que se almacenan en el website a modo de biblioteca de contenidos y a disposición del público para su consumo bajo demanda (Imagen 2). A continuación se expone una descripción de la programación completa de Podium Podcast ${ }^{7}$.

La colección de ficción agrupa la producción del género de ficción de forma continua. Bajo este primer nivel de catalogación, se incluyen tres programas: $E l$ gran apagón — novela radiada de entre 15 y 20 minutos por capítulo-, ¿En qué puedo ayudarle? - serie dramatizada que relata situaciones que rozan lo absurdo, cuya duración oscila entre 3 y 5 minutos - y El club del terror — con relatos del género, que transcurren en espacios de entre 15 y 25 minutos, aproximadamente-.

La colección de periodismo incluye reportajes de investigación y temas de actualidad en cinco programas ${ }^{8}$ : Le llamaban padre, con reportajes de investigación de entre 19 y 23 minutos por episodio; Los búfalos nocturnos, que «es la apuesta de Podium por el periodismo cultural, en colaboración con Babelia y la sección de cultura de El País», según detalla el sitio web, con espacios cercanos a los 25 minutos de duración. Igualmente, contiene el programa El mundo según Severino —con espacios de autor que exploran la creatividad radiofónica y con duraciones en torno a los 5 minutos - ; Micro — que agrupa reportajes, crónicas o documentales sonoros producidos por las diferentes marcas radiofónicas de Prisa Radio - y Diario de un náufrago - producción que repasa los asuntos de la actualidad política española en emisiones de entre 8 y 10 minutos de duración.

La colección de entretenimiento cuenta con siete programas. Es la más extensa y ejemplo de lo que denominamos formato mixto. Incluye las producciones Mañana empiezo - serie de capítulos sobre salud, consumo y estilos de vida en la sociedad contemporánea relacionados con la información de actualidad, que tienen una duración que oscila entre 8 y 12 minutos-; Educa como puedas - monólogos de Carles Capdevila sobre la responsabilidad de ser padres, en tono humorístico y también cercanos a los 8 minutos_- La redada - con reportajes, entrevistas y tertulias en relación a redes y sus comentarios (entre 3 y 9 minutos por episodio); Encuádrate - audio dramas que exploran las historias que hay detrás de obras de arte populares, de unos 14 minutos-; Poemarios - que recupera las voces de la literatura hispanoamericana, con espacios de 1 a 3 minutos -; Aviario — con breves metáforas que identifican aves con perfiles de usuarios de redes sociales en tono de humor, de duración no superior a los dos minutos - y Cinco sentidos - entrevistas a personajes famosos sobre los cinco sentidos, con episodios de 2 a 4 minutos de duración.

La colección de esenciales exhibe el archivo de Prisa Radio, colabora con su rentabilidad y muestra que Podium Podcast no solamente se focaliza en la creación de nuevas narrativas radiofónicas sino que hace visible los contenidos del departamento de Documentación de la Cadena SER. El objetivo inicial objetivo era dar mayor visibilidad a los fondos documentales, aportar valor añadido a la oferta radiofónica y colaborar con la acción formativa y de entretenimiento del medio. Aunque la idea embrionaria no cuajó, Podium Podcast asumió, como almacén de contenidos público, la inercia del proyecto. Por lo tanto, como sección pensada para la distribución de

7 Consulta realizada a fecha 29 de agosto de 2016.

8 A fecha 13 de septiembre de 2016. 
contenidos de archivo — entre ellos el audio drama-, confirma nuestra segunda hipótesis.

Actualmente, esenciales se nutre de contenidos del archivo histórico de Enciclomedi@ catalogados en cuatro subcolecciones: dos dramáticas y dos periodístico-informativas. Estas son Historias de medianoche - relatos de suspense de entre tres y cuatro episodios, que se radiaron por primera vez en 1987 y que tienen una duración máxima de 27 minutos—- Teatros del aire — que recupera las obras de teatro emitidas por la Cadena SER entre los años cincuenta y sesenta-, Acontecimientos históricos - narración de hechos históricos, donde ocasionalmente se utiliza el recurso a la dramatización con los fondos de archivo- y Grandes entrevistas - selección de entrevistas archivadas por Prisa Radio-. La estrategia seguida para la nutrir esta sección se basa en la idea de encontrar un equilibrio entre la custodia de los fondos y su difusión en la red, esto es, se trata de democratizar estos archivos siguiendo una lógica acumulativa basada en criterios temáticos, cronológicos o informativos. Así pues, en su período inicial, Podium Podcast ejemplifica que las nuevas formas de producción y distribución digitales son catalizadoras de la reutilización de contenidos de archivo, por un lado, y de la creatividad radiofónica, por el otro. Sin embargo, paradójicamente, sus contenidos no son sometidos a gestión documental. Mientras la producción de la ficción sonora bajo el indicativo de la Cadena SER es descrita de acuerdo a criterios documentales y archivada en Enciclomedi@, la producción propia de Podium Podcast no. Esta última se conserva únicamente en servidores internos y en copias de seguridad externas, lo que implica, en primer lugar, que no se incluyen en el repositorio permanente de Prisa Radio $\mathrm{y}$, en segundo lugar, que no se les añaden metadatos descriptivos que faciliten su recuperación lo que, en última instancia, tiene como fin su reutilización futura o, lo que es lo mismo, su rentabilización.

El hecho de que, desde un inicio, el proyecto de Podium Podcast no contemplase la gestión documental de sus propios contenidos - lo apropiado sería que toda su producción pasase a custodia permanente- se entiende como un error estratégico. No obstante, tanto la dirección del proyecto sujeto a estudio como la del servicio documental de la Cadena SER están trabajando de forma conjunta para solventar esta situación (Espinosa de los Monteros, 2016; Martínez Concejo, 2016). De tal forma que la producción ad hoc para Podium Podcast sea descrita y custodiada en Enciclomedi@.

\section{Conclusión}

Podemos concluir que Prisa Radio cuenta con un excelso registro de contenidos que custodia su producción. Aunque dicho archivo no está digitalizado en su totalidad, los fondos de ficción sonora sí lo están, lo que desmiente la primera hipótesis planteada y lleva a justificar el hecho de que no hayan sido reutilizados en la programación radiofónica durante años.

La segunda hipótesis formulada, sin embargo, sí se constata. Las nuevas formas de consumo digital, asincrónico y fragmentado son una nueva vía para la distribución de contenidos especializados y de archivo que no encuentran cabida en la programación tradicional, donde la inmediatez informativa es protagonista de la parrilla. Podium Podcast es una plataforma digital que, de forma general, distribuye 
contenidos atemporales y, de forma particular, cataliza la creación y redifusión de fondos de ficción sonora. Esto sería imposible sin un modelo documental o de gestión de contenidos que, por un lado, evidencie su potencialidad como fuente y, por el otro, que exija apurar el tratamiento documental de la producción de ficción actual, susceptible de recuperación y reutilización por su valor educativo, artístico e histórico.

Los resultados de este estudio, aunque limitados en términos de alcance, se presentan como una aproximación a las oportunidades que la tecnología digital ofrece no solo para la creación y la distribución de contenidos, sino también para la reutilización de fondos de archivo de acuerdo a criterios de trascendencia cultural. Criterio que cumple, sin lugar a dudas, la ficción sonora.

\section{Bibliografía}

Ávila, M. (2016). «'Las bicicletas son para el verano’ marcó la vuelta del radioteatro en la SER». Cadena SER. Recuperado de http://cadenaser.com/ser/2016/07/15/ cultura/1468583696_951919.html (Fecha de acceso: 01/09/2016).

Ayuso, E. (2013). «La recepción de la radio dramática en España (desde la posguerra a 1971)». Index. Comunicación, 3, 1, pp. 167-185.

Balsebre, A. (2001). Historia de la radio en España: Volumen 1, 1874-1939. Madrid: Cátedra.

Boletín Oficial del Estado. (2010). «Ley 7/2010, de 31 de marzo, General de la Comunicación Audiovisual». Recuperado de https:/www.boe.es/buscar/pdf/2010/BOE-A-2010-5292consolidado.pdf (Fecha de acceso: 01/09/2016).

Ávila, M. (2016). «'Las bicicletas son para el verano’ marcó la vuelta del radioteatro en la SER». Cadena SER. Recuperado de http://cadenaser.com/ser/2016/07/15/ cultura/1468583696_951919.html (Fecha de acceso: 01/09/2016).

Carrillo, M. V. y Nuño, M. V. (2010). «La documentación en la evaluación y gestión de la imagen corporativa». El profesional de la información, 19, 2, pp. 123-132.

Cazeaux, C. (2005). «Phenomenology and radio drama». British Journal of Aesthetics, 45, 2, pp. 157-174.

Cebrián, M. (2001). La radio en la convergencia multimedia. Barcelona: Gedisa.

Faustino, P. (2008). «RTP — Restructuring and Turnaround of a Public Service Broadcaster: Public Management with Private Attitude». Journal of Media Business Studies, 5, 3, pp. 51-78. DOI: 10.1080/16522354.2008.11073475.

Fernández, M; Rodríguez, D. y Rodríguez, M. (2013). «La gestión de contenidos como actividad estratégica en empresas de radiodifusión. Estudio de casos en la radio comercial española». El Profesional de la Información, 22, 5, pp. 392-398. Recuperado de: http:// goo.gl/f1S3YF (Fecha de acceso: 26/06/2016).

Franquet, R. y Fontana J. (1986). Història de la radiodifusió a Catalunya. Del naixement al franquisme. Barcelona: Edicions 62.

Gallego, J. I. (2012). «Podcasting in Spain: A New Business Model or a Reflection of Traditional Radio?». The Radio Journal, 10, 1, pp. 23-34. DOI: 10.1386/rjao.10.1.23_1.

Gallego, J. I. (2010). Podcasting: distribución de contenidos sonoros y nuevas formas de negocio en la empresa radiofónica española. [Tesis doctoral]. Madrid: Universidad Complutense de Madrid.

Gamarra, L. (2015). «El radioteatro quiere volver a las ondas». El Mundo. Recuperado de http://www.elmundo.es/madrid/2015/04/16/5530196ae2704edf178b456e.html (Fecha de acceso: 17/08/2016).

Guarinos, V. (1999). Géneros ficcionales radiofónicos. Sevilla: MAD.

Huwiler, E. (2005). «Storytelling by sound: A theoretical frame for radio drama analysis». 
The Radio Journal - International Studies in Broadcast and Audio Media, 3, 1, pp. 45-59. DOI: $10.1386 /$ rajo.3.1.45/1.

- (2010). «Radio Drama Adaptations. An Approach Towards an Analytical Methodology». Journal of Adaptation in Film \& Performance, 3, 2, pp. 129-140.

Jenkins, H. (2003). «Transmedia Storytelling. Moving Characters from Books to Films to Video Games Can Make Them Stronger and More Compelling». Technology Review. Recuperado de https://www.technologyreview.com/s/401760/transmedia-storytelling/ (Fecha de acceso: 4/10/2016).

Lewis, P. (2004). "Opening and Closing Doors: Radio Drama in the BBC». The Radio Journal International Studies in Broadcast and Audio Media, 1, 3, pp. 161-176. DOI: 10.1386/rajo.1.3.161/1.

Martínez, M. P. y Díez, J. R. (2005). Lenguaje, géneros y programas de radio. Introducción a la narrativa radiofónica. Pamplona: EUNSA.

Martínez, M. P. (2011). «La nueva organización de la producción». En Ortiz, M.A. y López, N. (Ed.), Radio 3.0. Una nueva radio para una nueva era. Madrid: Fragua, pp. 123-140.

Nieto, A. e Iglesias, F (2000). La empresa informativa. Barcelona: Ariel.

Oesterlen, E. M. (2009). «Lend Me Your 84 Million Ears: Exploring a Special Radio Event Shakespeare's King Lear on BBC World Service Radio». The Radio Journal, 6, 1, pp. 3344 DOI: 10.1386/rajo.6.1.33_1.

Podium Podcast. Recuperado de: http://www.podiumpodcast.com (Fecha de acceso: 20/08/2016).

Rodero, E. y Soengas, X. (2010). Ficción Radiofónica. Madrid: Instituto Radiotelevisión Española.

Rodero, E. (2005). «Recuperar la creatividad radiofónica: Razones para apostar por la radio de ficción». Anàlisi: Quaderns De Comunicació i Cultura, 32, pp. 133-146.

Rodríguez Pallares, M. (2015). «Integración y visibilidad de la gestión de contenidos, dos retos por alcanzar en el modelo de comunicación radiofónica digital. Análisis de los casos de SER, COPE y RNE». Revista General de Información y Documentación, 1, 25, pp. 191-213.

- (2016). «Propuesta conceptual de un modelo de gestión de contenidos y del conocimiento para la empresa radiofónica española». Revista Española de Documentación Científica, 39, 2. Recuperado de http://redc.revistas.csic.es/index.php/redc/article/viewArticle/930 (Fecha de acceso: 28/08/2016).

Salaverría, R. (2015). «Ideas para renovar la investigación sobre medios digitales». El Profesional de la Información, 24, 3, pp. 223-226. DOI: 10.3145/epi.2015.may.01.

Scolari, C. A. (2013). Narrativas transmedia: Cuando todos los medios cuentan. Barcelona: Deusto.

Stake, R. (2007). Investigación con estudio de casos. Madrid: Morata.

Tamayo, M. (1981). El proceso de la investigación cientifica: Fundamentos de investigación. México: Limusa.

Ventín, G. S. (2008). «El nacimiento de la radionovela en España: La muerte de Mr Stay», presentada en el Congreso Fundacional de la Asociación Española de Investigación de la Comunicación (AE-IC), celebrado en la Facultad de Comunicación de la Universidad de Santiago de Compostela, en enero de 2008.

\section{Entrevistas}

Martínez Concejo, Ana. Responsable de Documentación Cadena SER (08-07-2016).

Espinosa de los Monteros, María Jesús. Jefa del proyecto Podium Podcast (5-07-2016). 